\title{
A OUTRA FACE DO CRESCIMENTO ECONÔMICO DA AMÉRICA LATINA: A QUESTÃO DOS MENINOS E MENINAS EM SITUAÇÃO DE RUA*
}

Carlos Nelson dos Reis"

SÍNTESE - O presente texto tem por objetivo esboçar um cenário da contradição: riqueza e pobreza na América Latina. Não pretende trazer nenhuma novidade e nem mesmo esgotar um tema, já tão discutido por analistas e estudiosos de diferentes posições tanto ideológicas como teóricas. A idéia é reforçar o indicativo do recrudescimento dos problemas sócio-econômicos da região, em razão das recentes iniciativas dos governos dos principais países de ajustarem suas estruturas produtivas no sentido de acompanharem os movimentos das estruturas dos países desenvolvidos. Para tanto, o texto é desenvolvido em dois itens: o primeiro trata da questão do crescimento éconômico, o que tem sido um conteúdo privilegiado nos discursos dos governantes, e o segundo mostra o custo social deste crescimento, principalmente no referente aos desagregados sociais. Por fim, faz uma referência especial à questão dos meninos e meninas em situação de rua na América Latina.
ABSTRACT - This paper aims to outline a scenery of contradiction: wealth and poverty in Latin America. It doesn't pretend to bring novelties neither to conclude over a theme already so discussed by analysts and researchers of different ideological and theoretical positions. The idea is to enforce the indicative of the region's social and economic problems worsening, due to the recent initiatives of the main countries governments in order to adjust their productive structures to the movements of these structures in the developed nations. The subject is discussed in two parts. The first one handles the problem of the economic growth, which has been privileged in the governants discourses. The second part shows the social cost of this growth, specially concerning the social desaggregates. At last, it makes a special reference to the issue concerning the boys and girls living on the streets in Latin America.

Tema da conferência proferida na XXVII Conferencia Internacional del CIBS, na cidade de Hong Kong em 2/8/96.

* Coordenador do Departamento de Economia da Pontifícia Universidade Católica do Rio Grande do Sul.

\begin{tabular}{|l|l|l|l|l|l|} 
VERITAS & Porto Alegre & v. 42 & $\mathrm{n}^{\circ} 1$ & Março 1997 & p. 117-126 \\
\hline
\end{tabular}




\section{Introdução}

A América Latina, ao longo dos seus 496 anos de história política, econômica e social, apresenta um forte conjunto de contradições. Dentre essas, destaca-se a dicotomia: riqueza e pobreza permeando essa história. A região é rica em recursos naturais, possui um vasto contingente de mão-de-obra, ostenta uma estrutura produtivạ industrial consolidada (não está em questão o estágio dessa estrutura), e as séries estatísticas dos indicadores econômicos mostram, principalmente a partir da década de 50, significativos perfis de crescimento econômico. Em contrapartida; os indicadores sociais apresentam perfis extremamente negativos. Esses perfis, em última instância, indicam níveis degradantes de pobreza que se traduzem em diferentes formas.

O objetivo deste texto é esboçar um cenário dessa contradição: uma priorização do crescimento econômico em detrimento do desenvolvimento social. Não se pretende trazer nenhuma novidade e nem mesmo esgotar o tema, já tão exaustivamente discutido por analistas e estudiosos de diferentes posições tanto ideológicas como teóricas. A pretensão é reforçar a indicação de recrudescimento dos problemas sócio-econômicos na região, em razão das recentes iniciativas dos governos dos principais países de ajustarem suas estruturas produtivas no sentido de acompanharem os movimentos das estruturas dos países desenvolvidos.

Para tanto, o texto se desenvolverá em dois itens. O primeiro tratará da questão do crescimento econômico, o que, normalmente, tem sido conteúdo privilegiado no discurso dos governantes. O segundo item tentará mostrar o custo social desse crescimento, principalmente no referente aos desagregados sociais, tendo como referencial especial a questão dos meninos(as) de rua da América Latina. Por fim, fazem-se algumas considerações a respeito das perspectivas de curto e médio prazos das variantes destacadas: riqueza e pobreza na América Latina.

\section{1 - A dinâmica do crescimento econômico da América Latina}

As interpretações a respeito das causas do subdesenvolvimento da América Latina têm suas origens nos diagnósticos da Comissão Econômica para a América Latina (CEPAL), que foi criada no final da década de 40.

As análises cepalinas mostraram que, muito mais do que as restrições internas, as causas do subdesenvolvimento da região se originaram das relações comerciais entre os países desenvolvidos. Para chegar a tal conclusão, fundamentaram-se na concepção centro-periferia: o centro constituído pelos países tecnologicamente ávançados, ao passo que a periferia composta pelos países produtores e exportadores de máterias-primas. Mostraram, principalmente, a partir dos impactos da Grande Depressão, que essa relação comercial indicava, no longo prazo, uma tendência desigual dos termos de troca.

Assim, partindo da constatação da deterioração dos termos de intercâmbio, firmou-se na região o consenso de que a industrialização dos países periféricos poderia reverter a situação. Sendo assim, a industrialização deveria priorizar a 
produção dos bens que eram importados e para os quais havia mercado consumidor.

Na medida em que o diagnóstico cepalino orientava para um processo de industrialização que substituísse as importações, sinalizava para um equacionamento na lógica de formação de um círculo virtuoso, “[...] a industrialização reduziria a dependência com relação aos manufaturados exportados pelo centro, aumentaria 0 emprego e a renda interna, expandindo o mercado doméstico e propiciando a expansão da indústria" (Bastos, 1995, p. 176).

A influência da CEPAL para as economias latino-americanas é inquestionável. Entretanto, ao contrário do que esperavam os formuladores de políticas econômicas da época, a estratégia de industrialização via substituição de importações, que foi tão importante para o crescimento econômico, não foi suficiente para superar o subdesenvolvimento social.

Segundo algumas interpretações, o insucesso foi decorrência da frágil estrutura social dos países periféricos, que inibiu os efeitos dos investimentos sociais. Dentre essas fragilidades, destacam-se: distribuição desigual da renda e da terra, o reduzido grau de organização dos trabalhadores, o aumento das concentrações urbanas sem o estabelecimento de infra-estrutura necessária, etc.

Essa rápida retrospectiva, ainda que superficial, serve para ilustrar o fenomenal salto de crescimento econômico que as principais economias latinoamericanas obtiveram no decorrer das décadas de 50,60 e 70. Na realidade, a opção pela industrialização, muito mais do que uma busca para superar o subdesenvolvimento, traduziu-se em uma trajetória de crescimento acelerado.

Esse processo impôs o alargamento das diferenças entre pobreza e riqueza, que passaram a ter uma tipificação urbano-industrial e não mais rural-ágrario exportadora. Os dados a seguir, ao destacarem algumas das principais economias latino-americanas, têm o objetivo de situar o cenário de crescimento econômico, independentemente dos custos sociais que foram se acumulando.

As informações constantes na Tabela 1 permitem ter-se uma noção do grau de urbanização da região. Observa-se que, no início dos anos 90 , mais de $70 \%$ da população passou a concentrar-se no perímetro urbano.

Tabela 1

Percentual da população urbana na América Latina e em países selecionados - 1960/90

\begin{tabular}{lllll}
\hline PAÍSES & 1960 & 1970 & 1980 & 1990 \\
\hline Argentina & 73,6 & 78,4 & 82,9 & 86,3 \\
Brasil & 44,9 & 55,8 & 66,2 & 74,9 \\
Chile & 67,8 & 75,2 & 81,2 & 85,9 \\
México & 50,8 & 59,0 & 66,4 & 72,6 \\
América Latina & 49,2 & 57,2 & 64,9 & 71,5 \\
\hline
\end{tabular}

FONTE: BID. Relatório 1991. Seguridade Social. 
As principais regiões econômicas acompanham essa distribuição, sendo que Argentina e Chile chegam a ter $85 \%$ de suas populações localizadas nos respectivos perímetros urbanos. Chama-se atenção para os níveis do Brasil que em 1960, se situava em $44,9 \%$ e, em 1990 chegou a 74,9\%.

É importante atentar-se para a questão do crescimento urbano por dois motivos: primeiro, porque ele está diretamente relacionado com a evolução do crescimento industrial, e, segundo, porque é a partir da urbanização desenfreada que os problemas sociais originados na estrutura produtiva em transição vão surgir $e$ multiplicar-se. Essa questão será objeto do segundo item.

Assim, a opção pelo crescimento industrial dinamizou a estrutura produtiva latino-americana que passou a ostentar, nas décadas de 60 e 70, expressivas taxas de crescimento (Tabela 2).

Tabela 2

Taxa de crescimento média anual do PIB por tipo de despesa e setores de origens na América Latina - 1961-90

\begin{tabular}{lccc}
\hline ESPECIFICAÇÃO & $1961-70$ & $1971-80$ & $1981-90$ \\
\hline PIB & 5,4 & 5,9 & 0,9 \\
Consumo & 4,8 & 6,0 & 1,1 \\
Investimentos & 7,4 & 7,4 & $-3,2$ \\
Exportações & 5,8 & 4,7 & 5,0 \\
Importações & 5,8 & 8,2 & $-1,1$ \\
Setor Agrícola & 3,7 & 3,4 & 1,9 \\
Setor Industrial & 5,9 & 6,2 & 0,3 \\
Setor Serviços & 5,5 & 6,2 & 1,3 \\
\hline
\end{tabular}

FONTE: BID. Relatório 1991 - Seguridade Social.

Alguns itens chamam atenção. Os investimentos cresceram a uma taxa média anual da ordem de 7,0\% no período 1961-80, o que é, em boa parte, explicado pela entrada maciça de capitais das empresas multinacionais diferentes de segmentos produtivos. O desempenho das exportações, nesse mesmo período, serviu para financiar as importações que, em grande parte, foram de máquinas, instalações e tecnologia. A performance do setor agrícola comparativamente à do industrial confirma a opção pela mudança do modelo do crescimento. Por fim, as taxas de crescimento do setor serviços evidencia, de certa forma, o movimento de urbanização.

Dos países selecionados, destaca-se, no período 1961-80, o desempenho do Brasil e do Chile (Tabela 3): são economias que consolidaram grandes estruturas industriais, principalmente o Brasil nos anos 70 . 
Tabela 3

Taxa de crescimento média anual do PIB

em países selecionados da América Latina - 1961-90

\begin{tabular}{lccc}
\hline PAÍSES & $1961-70$ & $1971-80$ & $1981-90$ \\
\hline Argentina & 4,4 & 2,5 & $-1,9$ \\
Brasil & 5,4 & 8,6 & 1,3 \\
Chile & 4,2 & 2,6 & 2,7 \\
México & 7,0 & 6,7 & 1,5 \\
América Latina & 5,4 & 5,9 & 0,9 \\
\hline
\end{tabular}

FONTE: BD. Relatório 1991 - Seguridade Social.

O período 1981-90 (Tabelas 2 e 3) apresenta uma queda generalizada da atividade produtiva no conjunto da América Latina. Os investimentos tiveram uma taxa de crescimento média anual de $-3,2 \%$, o que percutiu nas taxas de crescimento dos setores industrial e serviços - $0,3 \%$ e 1,3 respectivamente (Tabela 2).

Finalmente, destaca-se que a opção pelo crescimento industrial trouxe para a região as seguintes situações: (a) uma estrutura produtiva industrial consolidada, mas ainda fundamentada nos parâmetros da segunda revolução industrial; (b) os impactos da crise produtiva e financeira, que se iniciou na segunda metade dos anos 70 nos países do primeiro mundo; (c) as crises recentes do capitalismo, tais como inflação, dívidas interna e externa, déficit público, altíssimo grau de intervenção estatal, câmbio desvalorizado; e, (d) forte recrudescimento das questões sociais, praticamente em todos os níveis. Se, no modelo rural-agrário exportador, já existia um considerável grau de demandas sociais insatisfeitas, agora, em um modelo urbano-industrial e ainda em crise, essas demandas se multiplicaram em uma progressão geométrica.

\section{2 - 0 custo do crescimento econômico}

O primeiro item teve como intenção ilustrar o comportamento da estrutura produtiva latino-americana frente aos desafios impostos pelas demandas dos capitais internos e externos. Não se pretende deixar implícita a ingenuidade de que todos os males, ou até mesmo todos os benefícios, da região se resumem ou se justificam pela opção econômica. É mais do que evidente que a variável política tem uma alta participação nessas decisões (isso tanto nos períodos de democracia como nos de ditadura civil e/ou militar). Na realidade, as grandes decisões, via de regra, definiram-se num ambiente político com determinações econômicas, com seus respectivos reflexos no campo social.

Neste segundo item, a preocupação é apontar os custos sociais advindos, especialmente, das rápidas transformações da estrutura produtiva. Para tanto, partese do pressuposto de que toda trajetória de crescimento econômico, quando não acompanhada de políticas sociais efetivas, aumenta as desigualdades sociais.

Esta, inquestionavelmente, é a situação da América Latina que, ao longo de sua história política econômica e social, evidencia a desigualdade social como 
uma constante. Quando do modelo de crescimento rural-agrário exportador, que vigorou até o final dos anos 40 , as desigualdades sociais já se faziam presentes e residiam, principalmente, na má distribuição da renda gerada, agora no vigor do modelo urbano-industrial, a questão se torna ainda mais complexa.

Para os objetivos desta reflexão, considera-se como um dos principais fatores geradores de exclusão social na América Latina a precariedade da distribuição da renda. É evidente que, junto ao comportamento dessa variável, uma série de outros fatos de cunho sócio-político concorrem para a perversidade dessa realidade.

A dimensão da desigualdade na distribuição da renda na região pode ser melhor entendida a partir das informações da Tabela 4.

Tabela 4

Comparação do PIB per capita de ricos e pobres - 1985-90

\begin{tabular}{|c|c|c|c|c|c|c|}
\hline \multirow[b]{2}{*}{ PAÍSES } & \multicolumn{2}{|c|}{$\begin{array}{l}\text { PARTTCIPAÇÃO } \\
\text { NA RENDA \% }\end{array}$} & \multicolumn{3}{|c|}{ PIB PER CAPITA US\$ } & \multirow{2}{*}{$\begin{array}{l}\text { RAZÄO } \\
\text { ENTRE } \\
\text { RICOS E } \\
\text { POBRES }\end{array}$} \\
\hline & $\begin{array}{l}\text { Ano } \\
\text { (1) }\end{array}$ & $\begin{array}{l}20 \% \\
\text { mais } \\
\text { pobres }\end{array}$ & $\begin{array}{l}20 \% \\
\text { mais } \\
\text { ricos }\end{array}$ & $\begin{array}{l}20 \% \text { mais } \\
\text { pobres }\end{array}$ & $\begin{array}{l}20 \% \text { mais } \\
\text { ricos }\end{array}$ & \\
\hline Brasil & 1989 & 2,1 & 67,5 & 245,89 & 7903,62 & 32,1 \\
\hline Colômbia & 1991 & 3,6 & 55,8 & 261,82 & 4058,28 & 15,5 \\
\hline Peru & 1986 & 4,9 & 51,4 & 241,72 & 2535,58 & 10,5 \\
\hline Venezuela & 1989 & 4,8 & 49,5 & 726,38 & 7490,80 & 10,3 \\
\hline Austrália & 1985 & 4,4 & 42,2 & 3705,55 & 35539,63 & 9,6 \\
\hline EUA & 1985 & 4,7 & 41,9 & 5447,32 & 48562,32 & 8,9 \\
\hline Canadá & 1987 & 5,7 & 40,2 & 5134,18 & 36209,48 & 7,1 \\
\hline França & 1989 & 5,6 & 41,9 & 6438,45 & 48173,43 & 7,5 \\
\hline Itália & 1986 & 6,8 & 41,0 & 7193,89 & 43347,95 & 6,0 \\
\hline Espanha & 1988 & 8,3 & 36,6 & 6101,29 & 26904,46 & 4,4 \\
\hline Índia & 1990 & 8,8 & 41,3 & 106,86 & 501,52 & 4,7 \\
\hline Bangladesh & 1989 & 9,5 & 38,6 & 98,75 & 401,23 & 4,1 \\
\hline
\end{tabular}

FONTE: Banco Mundial, relatório sobre o desenvolvimento mundial, 1994. (1) Ano de divulgação do dado.

O Brasil, uma das principais economias latino-americanas, é o país que apresenta a maior razão entre ricos e pobres: 32,1 vezes. Ou seja, o segmento composto pelos $20 \%$ mais pobres tem que ter condições de avançar em direção a essa razão para poderem ver diminuidas suas desigualdades. Nos países europeus listados, por exemplo, essa relação é muitas vezes menor: França 7,5, Itália 6,0 e Espanha 4,4. Adiciona-se ainda o fato de que, nesses países, a renda per capita do 


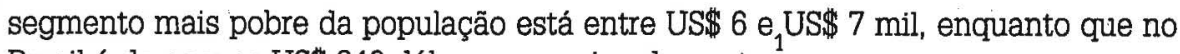
Brasil é de apenas US\$246 dólares, aproximadamente.

Com tal nível de desigualdade de renda, fica mais do que explicada a "letargia psicodepressiva" da qual a sociedade brasileira vem sendo paciente há alguns anos, o que se retrata no aumento constante, e em alguns casos acelerado, da violência urbana que, em alguns momentos, vem acompanhada por violências rurais, na criminalidade em suas diferentes modalidades, na prostituição, que assume dimensões nas idades infantil, adolescente e adulta e que, na versão atual, não é mais um qualificativo apenas feminino, mas também masculino, etc.

Tendo como referencial esse cenário, é possível aferir-se que o produto último e socialmente indesejado é o que vem proliferando pelas ruas da América Latina, principalmente nas ruas brasileiras: os meninos e meninas de rua.

É preciso destacar que não se trata de uma questão puramente contemporânea. Ela acompanha a evolução das civilizações e vem tomando espaço nos diferentes fóruns de discussões sociais e políticas.

A nível de América Latina, esse fenômeno começa a se fazer presente como pauta prioritária em diferentes congressos, conferências, simpósios, seminários, etc., nos últimos 10 anos, mais precisamente no decorrer dos anos 80, quando a presença de um número crescente de crianças nas ruas se tornou cada vez mais visível e incômoda. As características mais comuns da criança que vai para as ruas são as seguintes:

“- é prematuramente adulta e busca meios para sobreviver na rua, como consequiência de um sistema social que a marginaliza;

- atua permanentemente em atitude defensiva frente às pessoas, como resposta ao maltrato físico de que é objeto por parte do meio que a rodeia;

- satisfazer suas necessidades básicas e reais na própria rua e com o seu grupo de pares, dorme, come e trabalha;

- enfrenta crescentes dificuldades escolares que a leva à repetência e ao abandono dos estudos;

- desenvolve habilidades especiais que lhe permite sobreviver;

- é um produto da carência de afeto familiar e social, o que influi negativamente no seu crescimento harmônico integral; $e$

- O menino(a) de rua é forte, astuto dentro do seu próprio meio". (UNICEF/SAS/FUNABEM, apud Rizini, 1995, p.100).

Dada a velocidade das diferentes formas de manifestação dessa situação, torna-se tarefa difícil chegar a um número que efetivamente dimensione o problema. Existem muitas pesquisas que buscaram regionalmente apurar esse número $\mathrm{e}$, a partir daí, propor alternativas. Essas propostas, em sua grande maioria, acabam não tendo nenhum resultado positivo, pois são formuladas a partir de uma orientação de caráter paternalista, prática muito comum na América Latina, onde a ideo-

O Plano Real implantado no Brasil em julho de 1994 reduziu drasticamente a inflação no país e nesse sentido acabou melhorando a capacidade de compra dos salários dos $20 \%$ mais pobres. Isto não significa que houve mudança nos parâmetros de distribuição da renda. 
logia populista esteve e está muito presente nas ações dos governantes quando voltadas para os problemas sociais.

As informaçōes da Tabela 5 permitem visualizar a dimensão desse problema que, ainda que não tenha aflorado em sua plenitude, já amedronta as comunidades da região.

Tabela 5

População segundo a faixa etána e nível de pobreza e população total da América Latina - 1990

\begin{tabular}{lll}
\hline POPULAÇÃO & $\begin{array}{l}\text { NÚMERO } \\
\text { ABSOLUTO } \\
\text { (milhões) }\end{array}$ & $\%$ \\
\hline Menores de cinco anos & 56,7 & 12,9 \\
Menores de 18 anos & 186,7 & 42,3 \\
Abaixo da linha de pobreza & 180,7 & 40,9 \\
Menores de 18 anos abaixo da & & 17,5 \\
$\quad$ linha de pobreza & 77,4 & - \\
População total & 440,9 & \\
\hline
\end{tabular}

FONTE: RIZINI, Irene. Deserdados da sociedade. Rio de Janeiro: USU; 1995.

Algumas relações merecem destaque: o percentual de $42,3 \%$ indica que quase metade da população da região se encontra na faixa etária abaixo de 18 anos; 0 percentual de $40,9 \%$ indica que mais de um terço da população está abaixo da linha de pobreza; menores de 18 anos abaixo da linha de pobreza representam $17,5 \%$; o mais grave é que do total da população abaixo da linha de pobreza, $42,8 \%$ são menores de 18 anos. Esse número por si só dispensa comentários.

Nessa mesma linha de raciocínio, uma vez mais chama atenção a posição do Brasil. É o pais de maior população, um pouco mais de um terço do total da América Latina (Tabela 6), sendo que, do total da população brasileira, $74,9 \%$ se encontra no perímetro urbano (Tabela 1). Do total da população abaixo de 18 anos, 0 País responde por $33,2 \%$, ou seja, um terço dos jovens latino-americanos com menos de 18 anos são brasileiros (Tabela 6). Da população abaixo da linha de pobreza, o Brasil detém $37,7 \%$ do total da região e, dos menores de 18 anos abaixo da linha de pobreza, o País abarca $36,2 \%$ do total. É exatamente aí que deve residir a preocupaçăo dos governantes, pois $41,1 \%$ dos que estão abaixo da linha de pobreza são menores de 18 anos; soma-se a isso o fato de a taxa global de fecundidade brasileira ser de 3,3, ou seja, cada mulher teria, em média, três filhos. 
Tabela 6

América Latina: Indicadores Básicos, 1990

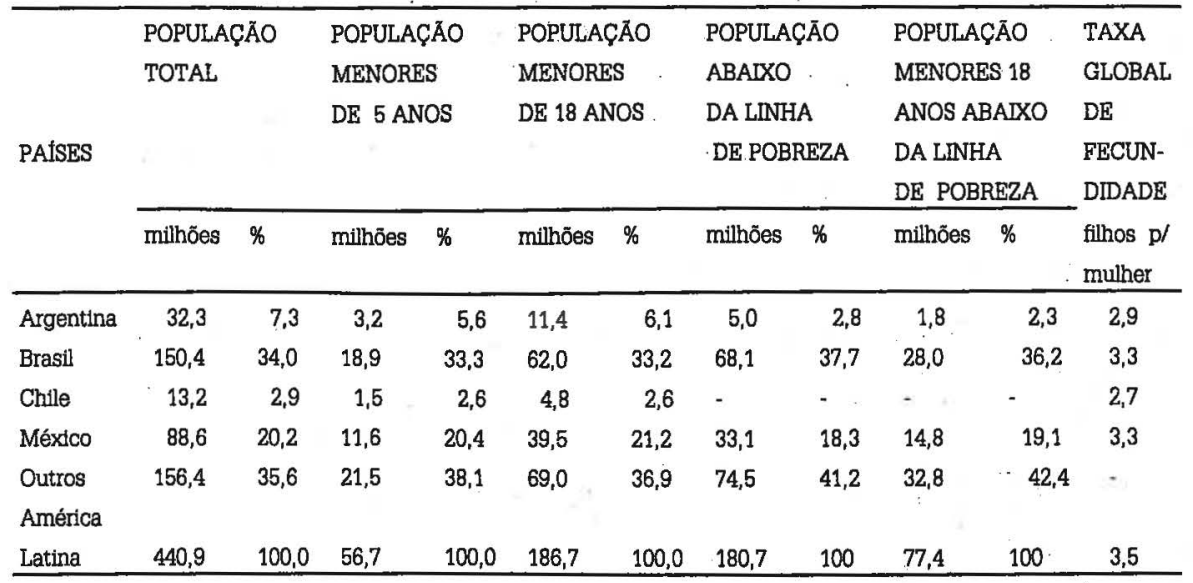

FONTE: RIZZINI. Deserdados da sociedade. Rio de Janeiro. USU. 1995.

Esse cenário mostra a outra face, tanto da rica e próspera América Latina, como do não menos rico e próspero Brasil, décima economia industrial do Mundo e sempre visto como o país do futuro (Tabela 6).

\section{Considerações finais}

Este texto não pretende ser catastrófico ou mesmo pessimista, pretende, sim, ser realista. Mostrar o outro lado do crescimento sempre vai resultar no encontro com uma situação que incomoda. A crítica que se faz à América Latina é quanto ao tamanho desse incômodo que, aos poucos, está se transformando em medo.

A questão dos meninos e meninas de e/ou na rua da América Latina não pode mais ser tratada apenas como um problema social de desvio de conduta, onde a solução, via de regra, está em criar instituições que recolhem essas crianças das ruas e lhes impõem, autoritariamente, estruturas de conceitos e valores formais que nada têm a ver com as suas origens e muito menos com a revolta de ser diariamente discriminado em razão do cheiro que exalam, da droga que ingerem para diminuir o frio e/ou a fome e da cor de sua epiderme, já que a maior parte é composta por índios e negros.

As instituições e a sociedade têm que perder a perversa cultura da compaixão, que normalmente é encaminhada por meio de políticas sociais com o fim de apenas compensar uma situação incômoda. É preciso adotar a cultura da paixão e, a partir desta, respeitar a cultura que esses meninos aprendem na dura luta pela sobrevivência.

É importante apontar, mais uma vez, que esse não é um problema puramente contemporâneo, mas é uma situação que vem se multiplicando geometricamente por meio do modelo urbano-industrial em vigor na região desde os anos 50 . 
Por fim, em termos de perspectivas, vê-se com tristeza que, em razão dos recentes movimentos de ajustes e reestruturação de algumas das principais economias latino-americanas, para uma vez mais buscar aproximar suas estruturas produtivas da dos países desenvolvidos - o que significa desemprego, recrudescimento da desestruturação da familia, prostituição, delinqüência e a rua como última alternativa - se ajusta a equação econômica em detrimento da equação social. Repito uma vez mais, não se pretendeu ser catastrófico ou mesmo pessimista. A verdade nunca é triste, ela pode não ter é jeito.

\section{Bibliografia}

BANCO INTERAMERICANO DE DESENVOLVIMENTO. Progresso sócio-econômico na América Latina. Seguridade Social: Relatório 1991.

BASTOS, Vania Lomônaco. Para entender as economias do terceiro mundo. Brasília; Ed. UNB, 1995.

COMISSION ECONOMICA PARA AMÉRICA LATINA Y EL CARIBE. Notas sobre la economia y el desenvollo. Informativo M. 585/586 deciembre 1995.

COMTTÊ INTERINSTITUCIONAL DE ARTICULAÇÃO DA ASSISTÊNCIA SOCIAL. I Conferência Estadual de Assistência Socia l- RS 1992 (anais).

DEBATE SOCIAL. Crianças e adolescentes. Brasília, ano 1, n.1, 1995.

MELLO, João Manuel Cardoso. O capitalismo tardio. São Paulo: Brasiliense, 1982.

PEREIRA, Luiz Bresser. Reformas econômicas em democracias novas: uma proposta social democrata. São Paulo: Nobel, 1996.

RIZZINI, Irene. Deserdados da Sociedade: Os meninos de rua da América Latina. Rio de Janeiro: USU Ed. Universitário, 1995. 